\title{
A validation study of the Hong Kong version of Montreal Cognitive Assessment (HK-MoCA) in Chinese older adults in Hong Kong
}

\author{
PY Yeung *, LL Wong, CC Chan, Jess LM Leung, CY Yung
}

\section{A B S T R A C T}

Objective: To validate the Hong Kong version of Montreal Cognitive Assessment (HK-MoCA) in identification of mild cognitive impairment and dementia in Chinese older adults.

Design: Cross-sectional study.

Setting: Cognition clinic and memory clinic of a public hospital in Hong Kong.

Participants: A total of 272 participants (dementia, $\mathrm{n}=130$; mild cognitive impairment, $\mathrm{n}=93$; normal controls, $\mathrm{n}=49$ ) aged 60 years or above were assessed using HK-MoCA. The HK-MoCA scores were validated against expert diagnosis according to the Diagnostic and Statistical Manual of Mental Disorders (4th ed) criteria for dementia and Petersen's criteria for mild cognitive impairment. Statistical analysis was performed using receiver operating characteristic curve and regression analyses. Additionally, comparison was made with the Cantonese version of Mini-Mental State Examination and Global Deterioration Scale.

Results: The optimal cutoff score for the HK-MoCA to differentiate cognitive impaired persons (mild cognitive impairment and dementia) from normal controls was $21 / 22$ after adjustment of education level, giving a sensitivity of 0.928 , specificity of 0.735 , and area under the curve of 0.920 . Moreover, the cutoff to detect mild cognitive impairment was 21/22 with a sensitivity of 0.828 , specificity of 0.735 , and area under the curve of 0.847 . Score of the Cantonese version of the Mini-Mental State Examination to

This article was published on 15 Aug 2014 at www.hkmj.org. detect mild cognitive impairment was $26 / 27$ with a sensitivity of 0.785 , specificity of 0.816 , and area under the curve of 0.857 . At the optimal cutoff of
18/19, HK-MoCA identified dementia from controls with a sensitivity of 0.923 , specificity of 0.918 , and area under the curve of 0.971 .

Conclusion: The HK-MoCA is a useful cognitive screening instrument for use in Chinese older adults in Hong Kong. A score of less than 22 should prompt further diagnostic assessment. It has comparable sensitivity with the Cantonese version of MiniMental State Examination for detection of mild cognitive impairment. It is brief and feasible to conduct in the clinical setting, and can be completed in less than 15 minutes. Thus, HK-MoCA provides an attractive alternative screening instrument to Mini-Mental State Examination which has ceiling effect (ie may fail to detect mild/moderate cognitive impairment in people with high education level or premorbid intelligence) and needs to be purchased due to copyright issues.

\section{Hong Kong Med J 2014;20:504-10 DOI: $10.12809 / \mathrm{hkmj} 144219$

\footnotetext{
${ }^{1}$ PY Yeung *, MB, ChB, MRCP (UK)

${ }^{2}$ LL Wong, FHKCPsych, FHKAM (Psychiatry)

${ }^{3}$ CC Chan, MRCP (UK), FHKCP

2 JLM Leung, MRCPsych, FHKCPsych
} \\ CY Yung, FHKCP, FHKAM (Medicine)}

${ }^{1}$ Department of Rehabilitation, Kowloon Hospital, 147A Argyle Street, Hong Kong

2 Department of Psychiatry, United Christian Hospital, Kwun Tong, Hong Kong

Department of Medicine and Geriatrics, United Christian Hospital, Kwun Tong, Hong Kong

* Corresponding author: yeunpy3@ha.org.hk

\section{New knowledge added by this study}

- This study verified that the Hong Kong version of Montreal Cognitive Assessment (HK-MoCA) has high diagnostic accuracy for detection of dementia (sensitivity, 92.3\%; specificity, 91.8\%).

- It is a reasonably good screening tool for mild cognitive impairment with comparable efficacy with the Cantonese version of Mini-Mental State Examination (MMSE).

Implications for clinical practice or policy

HK-MoCA is brief and feasible to conduct in the clinical setting, and can be completed in less than 15 minutes.

- HK-MoCA provides an attractive screening instrument in place of MMSE which has ceiling effect and needs to be purchased due to copyright issues.

\section{Introduction}

Dementia implies decline in cognitive function interfering with an individual's life. Mild cognitive impairment $(\mathrm{MCI})$ is a clinical transitional state in which a person is cognitively impaired, typically in the memory domain, which is greater than that 
expected for a person at the given age and education level. A longitudinal study revealed that MCI patients proceeded to overt dementia at a rate of $10 \%$ to $15 \%$ per year, compared with a rate of $1 \%$ to $2 \%$ in control subjects. ${ }^{1}$ This implies that MCI patients have high risk of progressing to dementia. Prevalence of MCI varies widely, depending on the diagnostic criteria used and population studied. Its prevalence ranges from $3 \%$ to $13 \%$ in people above 65 years of age. ${ }^{2}$ Hence, identification of MCI patients is important for successful implementation of preventive strategies and early interventions. In practice, cognitive screening tools are used to detect persons with cognitive impairment who then undergo a detailed assessment process to ascertain the subtype, severity, caregiver status, and the presence of behavioural and psychological symptoms of dementia.

The Mini-Mental State Examination (MMSE) is the most widely used screening tool introduced by Folstein et al in $1975 .{ }^{3}$ It was originally designed for screening Alzheimer's disease and does not encompass all cognitive deficits. It has several well-known drawbacks, including low level of task difficulty, likelihood of ceiling effects (ie may fail to detect mild/moderate cognitive impairment in people with high education level or premorbid intelligence), and narrow range of cognitive domains assessed. Consequently, it has low sensitivity for MCI patient detection. The Cantonese version of Mini-Mental State Examination (CMMSE) was translated and validated by Chiu et al in $1994^{4}$ with good sensitivity (97.5\%) and specificity (97.3\%) to discriminate subjects with moderate-to-severe dementia from normal subjects.

The Montreal Cognitive Assessment (MoCA) is a brief and potentially useful screening tool developed and validated by Nasreddine et al. ${ }^{5}$ It was conceptualised in MCI patients performing within a normal range on the MMSE. The MoCA is a onepage test with a maximum score of 30 . One point is added if the person has 12 years of education or less. A score of 23 to 26 represents MCI, 17 to 22 represents moderate impairment, and 16 or below represents severe impairment suggesting dementia. ${ }^{6}$ The original validation study of MoCA reported a sensitivity of $100 \%$ and specificity of $87 \%$ in detecting mild Alzheimer's disease using a cutoff score of 26. It reported a sensitivity of $90 \%$ in detecting MCI. ${ }^{6}$ It was validated to detect cognitive impairment in different clinical populations including those with Parkinson's disease, brain metastases and stroke, and had established cross-cultural performance in detecting MCI and dementia. ${ }^{7-12}$ However, educational adjustment and cutoffs varied. In a Korean study, a cutoff score of $22 / 23$ yielded a sensitivity of $89 \%$ and specificity of $84 \%$ for screening MCI. ${ }^{7}$ A study in mainland China suggested 20/21 as cutoff score (Xie He Hospital version) with $84.6 \%$ sensitivity and $76 \%$

\section{以香港華籍老年人為對象的《蒙特利爾認知評估 量表》香港版的驗證研究 \\ 楊佩如、黃璐璐、陳鎮中、梁琳明、翁祖耀}

目的：對《蒙特利爾認知評估量表》香港版（HK-MoCA）能否區分 華籍老年人的輕度認知障礙和老年癡呆症進行驗證。

設計：橫斷面研究。

安排：香港一所公立醫院的認知診所和記憶診所。

參與者：共272名60歲或以上的人士參與本研究, 其中包括老年癡 呆症患者 130 人、輕度認知障礙患者 93 人和正常對照組 49 人。使用 HK-MoCA為他們進行評估。根據《精神疾病診斷與統計手冊》（第 四版）中對老年癡呆症和Petersen等人制定的輕度認知障礙診斷標準 作準則, 為HK-MoCA進行驗證。採用受試者工作特徵曲線和迴歸分 析進行統計分析, 亦與《簡易精神狀態檢查》粵語版和《全球衰退量 表》進行比較。

結果：在調整教育水平後, HK-MoCA中區分認知障礙者（輕度認知 障礙和老年癡呆症）與正常對照組的最佳截取值為 $21 / 22$; 得出的敏 感性為 0.928 、特異性 0.735 和曲線下方面積 0.920 。此外, 區分輕度 認知障礙的截取值為 $21 / 22$; 得出的敏感性為 0.828 、特異性 0.735 和 曲線下方面積 0.847 。《簡易精神狀態檢查》粵語版區分輕度認知障 礙的截取值為 $26 / 27$; 得出的敏感性為 0.785 、特異性 0.816 和曲線下 方面積 0.857 。使用最佳截取值為 $18 / 1$ 時, HK-MoCA區分老年癡 呆症與正常對照組的敏感性為 0.923 、特異性 0.918 和曲線下方面積 0.971 。

結論：對於香港華籍老年人來説, HK-MoCA是一個有用的認知篩 選工具。HK-MoCA分數低於 22 分的老年人應及時作進一步診斷評 估。HK-MoCA的敏感性與《簡易精神狀態檢查》粵語版相若。HKMoCA不但簡單, 且可作臨床應用, 參與者還可以在 15 分鐘內完成。 《簡易精神狀態檢查》粵語版本身有「天花板效應」（即對受高教育 程度或患病前智力較高的人的輕度 / 中度退化較難區分 ）, 而且因版 權問題須購買才可使用。所以, HK-MoCA可作為認知功能受損另一 種籂檢工具。

specificity. ${ }^{8}$ It was the same as the Hong Kong version: $73 \%$ sensitivity and $75 \%$ specificity for patients with small vessel disease (SVD). ${ }^{13}$ Furthermore, the original MoCA has high level of internal consistency (Cronbach's alpha of 0.83 ) and test-retest reliability (correlation coefficient $=0.92, \mathrm{P}<0.001) .{ }^{5}$

This study employed the Hong Kong version of MoCA (HK-MoCA) which has been validated in Chinese patients with cerebral SVD by Wong et al. ${ }^{13}$ The primary objective was to evaluate the HK-MoCA as a screening tool in identification of MCI and dementia in Chinese older adults, and to determine the corresponding optimal cutoff points. In addition, the ability of HK-MoCA in discriminating dementia subtypes was examined.

\section{Methods}

\section{Participants}

This was a cross-sectional validation study performed from August 2011 to June 2013 to validate HK-MoCA 


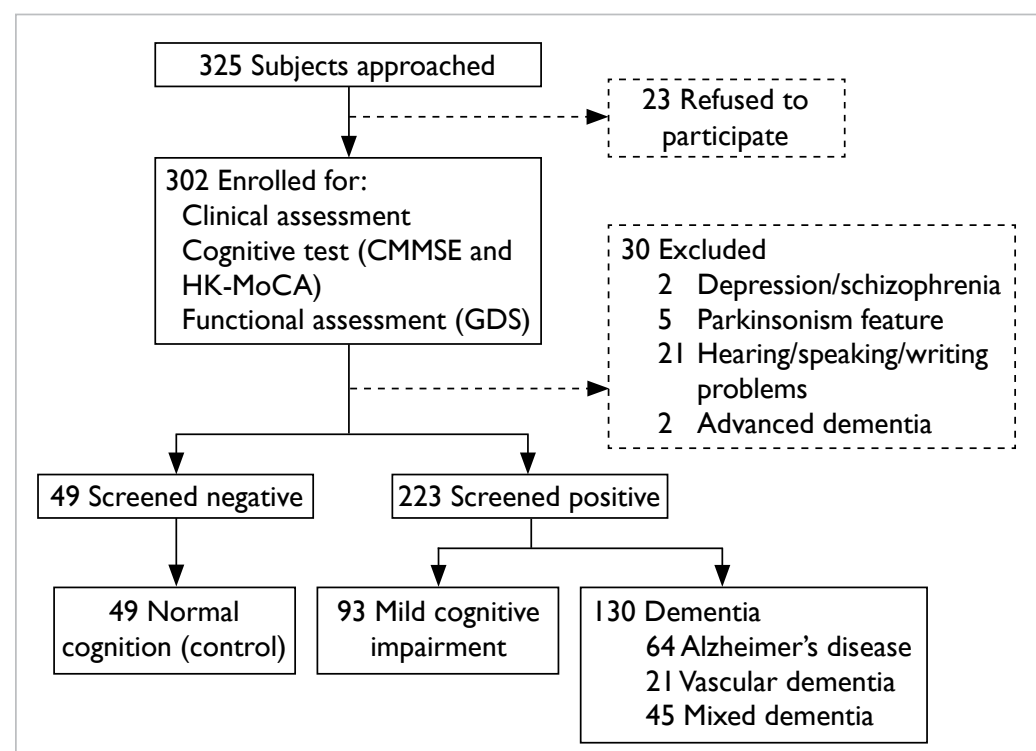

FIG. Flowchart of participant recruitment

Abbreviations: CMMSE = Cantonese version of Mini-Mental State Examination; GDS = Global Deterioration Scale; HK-MoCA = Hong Kong version of Montreal Cognitive Assessment

\section{Measurements}

\section{Clinical assessment}

Basic demographic information (age, gender, and education level), cardiovascular risk factors (diabetes mellitus, hypertension, hyperlipidaemia, coronary heart disease, and stroke) as well as clinical information about drinking and smoking habits was collected. Besides, a semi-structured mental status examination and a comprehensive neuropsychological battery (including biochemical screening and cerebral imaging tests) were performed for making a final cognitive diagnosis by experienced geriatricians and psychogeriatricians according to the DSM-IV (Diagnostic and Statistical Manual of Mental Disorders, 4th edition) criteria ${ }^{14}$ for dementia and Petersen et al's criteria for MCI. ${ }^{6}$ The HK-MoCA scores were validated against expert diagnoses.

\section{Cognitive assessment}

The CMMSE and HK-MoCA were administered to each subject at the same consultation. The administration was standardised and was done in turn by two investigators. The HK-MoCA had more questions and was harder than CMMSE. To avoid frustration, CMMSE was administered before HKMoCA. Fatigue may reduce attention span and increase the likelihood of error. Hence, there was a 5-to-10-minute break to minimise the fatigue effect.

Functional decline of demented subjects was as a cognitive screening instrument. It was conducted at the Cognition Clinic of Department of Medicine and Geriatrics and the Memory Clinic of Department of Psychiatry in a general hospital (United Christian Hospital) of Hong Kong. Cantonese-speaking Chinese adults aged 60 years or above, who were seen for suspected cognitive impairment and gave consent, were recruited. They were divided into three groups: subjects with dementia, subjects who met the criteria for $\mathrm{MCI}$, and cognitively normal controls (NC). Besides, NC were recruited from those who attended clinics of other subspecialties or elderly vaccination programmes under Department of Medicine and Geriatrics.

Patients were excluded if they had a history, as documented in medical records, of neurodegenerative disorders, central nervous system infection, brain tumour, significant head trauma, subdural haematoma, epilepsy, significant psychiatric disorders (such as major depression or schizophrenia), substance abuse, or alcoholism. Besides, persons with inability to use a pen or with communication barriers such as deafness or significant language or speech problem were also excluded. Last of all, advanced dementia patients with Global Deterioration Scale (GDS) stage 6 or above were not recruited. The flowchart of participant recruitment is shown in the Figure. Ethical approval was obtained from the Kowloon Central/Kowloon East Cluster Clinical Research Ethics Committee of the Hospital Authority. determined using the GDS. It predicted a patient's ability to function, as reflected in activities of daily living (ADL) and instrumental ADL as well as psychiatric morbidity on the basis of progressive cognitive delcine. ${ }^{9}$ It is composed of seven stages defined by a set of clinical characteristics. Stages 1 to 3 are pre-dementia stages. Stages 4 to 7 are dementia stages. Beginning in stage 5 , an individual can no longer survive without assistance.

\section{Sample size calculation}

Statistical software, MedCalc V12.3.0.0, was used for sample size calculation. Based on a previous study, ${ }^{15}$ the estimated prevalence rates of MCI and dementia were $8.5 \%$ and $12.5 \%$, respectively. The overall sample size was determined to be 138 (NC:MCI:dementia=1:1:1) with a power of 0.8 and a type I error of 0.05 . In the receiver operating characteristic (ROC) curve analyses of normal versus cognitive impaired groups, a sample of 90 from the positive group would achieve $90 \%$ power to detect a difference of 0.12 between the area under the curve (AUC) of alternative hypothesis and an AUC under the null hypothesis of 0.9000 (for MoCA) using a two-sided $z$-test at a significance level of 0.05 .

\section{Statistical analyses}

All statistical analyses were performed using the Statistical Package for the Social Sciences (SPSS) 
version 17.0 and a difference with a $\mathrm{P}$ value of $<0.05$ was regarded as statistically significant (two-tailed test). Group differences in demographic characteristics and various medical diseases were examined using one-way analysis of variance or Chi squared test for categorical data. Pairwise comparisons were performed afterwards with the significance level adjusted by the Bonferroni method. For differences attaining statistical significance, multivariate linear regression was performed to examine the influence upon performance of the HK-MoCA total score.

Inter-rater reliability was reflected by intraclass correlation coefficients with a sub-sample of 20 participants (persons with cognitive impairment and NC) being tested 2 to 4 weeks apart. Convenience sampling was employed with 10 participants by each investigator. According to the optimal cutoff points suggested in this study, five of them were $\mathrm{NC}$, four were persons with $\mathrm{MCI}$, and 11 were demented persons. Internal consistency was measured using Cronbach's alpha which measured pairwise correlations between tested items. Criterion validity was assessed using ROC analysis which gave the sensitivity and specificity of HK-MoCA at different cutoff points. With that, optimal cutoff scores were chosen using highest Youden index (sensitivity - [1 - specificity $])$. In case the indexes were very close between the two scores, the one with higher sensitivity would be chosen. The CMMSE and GDS scores were used to test the concurrent validity. The relationships between the performance of HKMoCA, CMMSE, and GDS were evaluated using Pearson and Spearman's rho correlation coefficients. Finally, the discriminatory power of individual cognitive domains was explored by examining any significant difference in scores among the three groups.

\section{Results}

A total of 272 eligible subjects completed the HK-MoCA screening in which 49 were NC, 93 were MCI subjects, and 130 were demented subjects (99 with mild and 31 with moderate severity of dementia). Of all the subjects with dementia, 49.2\% had Alzheimer's disease, $16.2 \%$ had vascular dementia, and $34.6 \%$ had dementia of mixed aetiology. The administration time depended on the education level and severity of cognitive impairment, and was around 10 to 15 minutes.

\section{Demographic and clinical characteristics}

Sample characteristics are summarised in Table 1. Overall, $60 \%$ of recruited subjects were females with a mean ( \pm standard deviation) age of $77.41 \pm 7.53$ years. The level of education was primary and below in $76 \%$ of the participants, with a mean of $4.21 \pm 4.43$ years of education. Significant differences among the three groups (NC, MCI, and dementia) were found in the variables of age $(\mathrm{F}[2,269]=13.230, \mathrm{P}<0.001)$, years of education ( $\mathrm{F}[2,269]=6.502, \mathrm{P}=0.002)$, HK-MoCA score (F $[2,269]=126.892, \quad \mathrm{P}<0.001)$, CMMSE score $(F[2,269]=152.868, \mathrm{P}<0.001)$, and GDS score $(\mathrm{F}[2,269]=933.751, \mathrm{P}<0.001)$. There was no significant difference among the three cognition groups by gender (Chi squared test $=3.653, \mathrm{P}=0.161$ ). Subjects in the dementia group were significantly older $(79.53 \pm 6.84$ years; $\mathrm{P}<0.001)$ and had less years of education $(3.26 \pm 4.03$ years; $\mathrm{P}=0.002)$ than those in the other two groups. In contrast, no

TABLE I. Demographic characteristics by cognition group*

\begin{tabular}{|c|c|c|c|c|c|c|}
\hline Demographic characteristic & NC $(n=49)$ & $\mathrm{MCI}(\mathrm{n}=93)$ & $\begin{array}{c}\text { Dementia } \\
(n=130)\end{array}$ & Total $(n=272)$ & $\mathbf{F}$ & $P$ value \\
\hline Gender (female) & $29(59 \%)$ & $49(53 \%)$ & $85(65 \%)$ & $163(60 \%)$ & - & $\chi^{2}=3.653 ; P=0.161$ \\
\hline Age (years) & $73.61 \pm 7.56$ & $76.45 \pm 7.54$ & $79.53 \pm 6.84$ & $77.41 \pm 7.53$ & 13.230 & $<0.001$ \\
\hline Years of education & $5.61 \pm 4.27$ & $4.80 \pm 4.78$ & $3.26 \pm 4.03$ & $4.21 \pm 4.43$ & 6.502 & 0.002 \\
\hline GDS score & $1.35 \pm 0.48$ & $2.86 \pm 0.35$ & $4.24 \pm 0.43$ & $3.25 \pm 1.16$ & 933.751 & $<0.001$ \\
\hline CMMSE score & $27.47 \pm 2.49$ & $22.57 \pm 4.16$ & $16.98 \pm 3.89$ & $20.78 \pm 5.50$ & 152.868 & $<0.001$ \\
\hline HK-MoCA total score & $22.59 \pm 3.99$ & $16.41 \pm 4.96$ & $11.30 \pm 3.98$ & $15.08 \pm 6.03$ & 126.892 & $<0.001$ \\
\hline Visuospatial and executive functioning & $3.67 \pm 1.21$ & $2.47 \pm 1.36$ & $1.27 \pm 1.23$ & $2.11 \pm 1.56$ & 69.154 & $<0.001$ \\
\hline Naming & $2.49 \pm 0.71$ & $2.02 \pm 1.01$ & $1.65 \pm 1.06$ & $1.93 \pm 1.03$ & 13.662 & $<0.001$ \\
\hline Attention & $5.00 \pm 1.19$ & $4.23 \pm 1.59$ & $3.12 \pm 1.59$ & $3.84 \pm 1.69$ & 31.482 & $<0.001$ \\
\hline Language & $2.88 \pm 0.33$ & $2.51 \pm 0.58$ & $2.21 \pm 0.54$ & $2.43 \pm 0.58$ & 30.516 & $<0.001$ \\
\hline Abstract reasoning & $0.78 \pm 0.74$ & $0.37 \pm 0.57$ & $0.25 \pm 0.49$ & $0.39 \pm 0.60$ & 15.111 & $<0.001$ \\
\hline Delayed recall & $2.06 \pm 1.69$ & $0.30 \pm 0.82$ & $0.05 \pm 0.28$ & $0.50 \pm 1.15$ & 96.871 & $<0.001$ \\
\hline Orientation & $5.71 \pm 0.61$ & $4.52 \pm 1.54$ & $2.75 \pm 1.39$ & $3.89 \pm 1.77$ & 101.798 & $<0.001$ \\
\hline
\end{tabular}

Abbreviations: CMMSE = Cantonese version of Mini-Mental State Examination; GDS = Global Deterioration Scale; HK-MoCA = Hong Kong version of

Montreal Cognitive Assessment; $\mathrm{MCl}=$ mild cognitive impairment; $\mathrm{NC}=$ normal controls

* Data are shown as mean \pm standard deviation, unless otherwise specified 
significant differences were demonstrated among the three subgroups of dementia (Alzheimer's disease, vascular dementia, and mixed dementia) in terms of age $(\mathrm{F}[2,127]=2.873, \mathrm{P}=0.060)$, years of education $(\mathrm{F}[2,127]=0.630, \mathrm{P}=0.534)$, HK-MoCA score $(\mathrm{F}[2,127]=0.428, \mathrm{P}=0.653)$, CMMSE score (F $[2,127]=0.322, \quad \mathrm{P}=0.725)$, and GDS score (F $[2,127]=0.161, \mathrm{P}=0.851)$.

There was no significant difference between those with dementia and $\mathrm{NC}$ in terms of drinking and smoking habits, and various medical conditions, except for stroke $(\mathrm{P}=0.031)$. The result was reasonable

TABLE 2. Effect of age, education, and diagnostic groups (NC, MCl, and dementia) on HK-MoCA total scores (multivariate linear regression)

\begin{tabular}{|c|c|c|c|c|c|}
\hline & \multicolumn{2}{|c|}{$\begin{array}{l}\text { Unstandardised } \\
\text { coefficients }\end{array}$} & \multicolumn{2}{|c|}{$\begin{array}{c}\text { Standardised } \\
\text { coefficients }\end{array}$} & \multirow[t]{2}{*}{$P$ value } \\
\hline & B & Standard error & Beta & $\mathbf{T}$ & \\
\hline Constant & 21.752 & 2.692 & - & 8.081 & $<0.001$ \\
\hline Age & -0.022 & 0.034 & -0.027 & -0.628 & 0.530 \\
\hline Years of education & 0.433 & 0.057 & 0.318 & 7.584 & $<0.001$ \\
\hline $\mathrm{MCl}$ & -5.769 & 0.696 & -0.454 & -8.286 & $<0.001$ \\
\hline Dementia & -10.147 & 0.688 & -0.842 & -14.751 & $<0.001$ \\
\hline
\end{tabular}

Abbreviations: HK-MoCA = Hong Kong version of Montreal Cognitive Assessment; $\mathrm{MCl}=$ mild cognitive impairment; $\mathrm{NC}=$ normal controls

TABLE 3. Optimal cutoff scores and psychometric properties of HK-MoCA and CMMSE for identifying $\mathrm{MCl}$ and dementia

\begin{tabular}{|c|c|c|}
\hline & HK-MoCA & CMMSE \\
\hline \multicolumn{3}{|c|}{ Distinction between cognitively impaired ( $\mathrm{MCl}+$ dementia) and normal controls } \\
\hline Optimal cutoff score & $21 / 22$ & $26 / 27$ \\
\hline Sensitivity & 0.928 & 0.915 \\
\hline Specificity & 0.735 & 0.755 \\
\hline AUC (unadjusted, SE) & $0.915(0.021)^{\star}$ & $0.931(0.017)^{*}$ \\
\hline AUC (education level adjusted, SE) & $0.920(0.020)^{*}$ & $0.933(0.017)^{\star}$ \\
\hline \multicolumn{3}{|c|}{ Distinction between $\mathrm{MCl}$ and normal controls } \\
\hline Optimal cutoff score & $21 / 22$ & $26 / 27$ \\
\hline Sensitivity & 0.828 & 0.785 \\
\hline Specificity & 0.735 & 0.816 \\
\hline AUC (unadjusted, SE) & $0.839(0.035)^{*}$ & $0.856(0.033)^{\star}$ \\
\hline AUC (education level adjusted, SE) & $0.847(0.035)^{*}$ & $0.857(0.033)^{\star}$ \\
\hline \multicolumn{3}{|c|}{ Distinction between dementia and normal controls } \\
\hline Optimal cutoff score & $18 / 19$ & $24 / 25$ \\
\hline Sensitivity & 0.923 & 0.954 \\
\hline Specificity & 0.918 & 0.898 \\
\hline AUC (unadjusted, SE) & $0.969(0.013)^{\star}$ & $0.985(0.007)^{*}$ \\
\hline AUC (education level adjusted, SE) & $0.971(0.012)^{\star}$ & $0.987(0.006)^{\star}$ \\
\hline
\end{tabular}

Abbreviations: $\mathrm{AUC}=$ area under the curve; CMMSE $=$ Cantonese version of Mini-

Mental State Examination; HK-MoCA = Hong Kong version of Montreal Cognitive

Assessment; $\mathrm{MCl}=$ mild cognitive impairment; $\mathrm{SE}=$ standard error

* $P \leq 0.001$ as stroke is a known cause of dementia.

\section{Score distribution of Hong Kong version of Montreal Cognitive Assessment}

From the original MoCA study, differences across cognition groups were more pronounced using MoCA than MMSE. ${ }^{5}$ This study did not reproduce the wide dispersion of MoCA scores and, indeed, mean scores of HK-MoCA of various groups were lower in general. The results were justified by the generally low education level of local Chinese older adults.

\section{The effect of age and education level}

The appropriateness of original education adjustment of MoCA total score was uncertain in local Chinese older adults. This study examined the effect of age and education level upon the performance of HK-MoCA by regressing the unadjusted raw score of HK-MoCA on age, years of education, and clinical diagnosis using multivariate linear models. The results are summarised in Table 2. There was a positive relationship between years of education and performance on HK-MoCA $(\beta, 0.318 ; \mathrm{P}<0.001)$ independent of age and clinical diagnosis. The effect of age was not significant $(\mathrm{P}=0.530)$.

The original MoCA recommendation of adding one point to subjects with 12 years of education or less was probably unsuitable here. In this study, the level of education in $76 \%$ of subjects was primary and below. Only 11 (4\%) subjects had more than 12 years of education. For this reason, we adopted a lower level of education adjustment to 6 years of education which had been employed by studies in China, ${ }^{8,10}$ Korea, ${ }^{7}$ and Hong Kong. ${ }^{13}$ Using this adjustment for education level, regression $\mathrm{R}^{2}$ coefficient was 0.587 . Thus, more than half of the variation in HK-MoCA was explained by the model.

\section{Psychometric properties of Hong Kong version of Montreal Cognitive Assessment}

Intraclass correlation coefficient for the interrater reliability was $0.987(\mathrm{P} \leq 0.001)$. Besides, the Cronbach's alpha score was 0.767 , indicating a high level of internal consistency. Comparison of GDS, CMMSE, and HK-MoCA scores between NC, MCI, and dementia groups showed that the severity level of cognitive impairment graded by GDS score was significantly correlated with HK-MoCA score with Spearman's rho correlation coefficient of -0.739 $(\mathrm{P} \leq 0.001)$. Similarly, Pearson correlation coefficient of CMMSE with HK-MoCA scores was 0.894 $(\mathrm{P} \leq 0.001)$. Together, it supported high concurrent validity of $\mathrm{HK}-\mathrm{MoCA}$.

Criterion validity of the adjusted HK-MoCA score was examined using ROC analysis. Various optimal cutoff scores are listed in Table 3. The 
optimal cutoff score for HK-MoCA to differentiate persons with cognitive impairment (MCI and dementia) from $\mathrm{NC}$ was $21 / 22$, giving a sensitivity of 0.928 , specificity of 0.735 , and AUC of 0.920 (95\% confidence interval [CI], 0.881-0.959). Moreover, the cutoff to detect $\mathrm{MCI}$ was also $21 / 22$ with a sensitivity of 0.828 , specificity of 0.735 , and AUC of 0.847 (95\% CI, 0.778-0.902). For comparison, CMMSE score to detect MCI was $26 / 27$ with a sensitivity of 0.785 , specificity of 0.816 , and AUC of 0.857 . The optimal cutoff score for HK-MoCA to detect dementia was $18 / 19$ with a sensitivity of 0.923 , specificity of 0.918 , and AUC of 0.971 (95\% CI, 0.935-0.991).

\section{Discriminatory ability}

The HK-MoCA total score and seven cognitive domain scores discriminated $\mathrm{NC}, \mathrm{MCI}$, and dementia groups in a stepwise fashion. In general, demented participants performed most poorly, followed by the MCI participants. Like the original study, delayed recall task was the first and most impaired domain in MCI participants. Besides, sample participants with GDS score equal to 4 were used to examine the discriminatory ability in differentiating subtypes of dementia; no significant difference was demonstrated ( $P$ values ranged from 0.243 to 0.672 ). The generally low education level and small dementia subgroup sample size might have compromised the results.

\section{Discussion}

\section{Validity and clinical utility of the Hong Kong version of Montreal Cognitive Assessment}

This study verified that HK-MoCA has high diagnostic accuracy for detecting dementia subjects (92.3\% sensitivity, $91.8 \%$ specificity). It is reasonably good and comparable with CMMSE in screening for MCI. The original MoCA by Nasreddine et $\mathrm{al}^{5}$ in 2005 and other validation studies of MoCA in different languages established the superiority to MMSE. Explanations are that MMSE did not test complex cognitive impairments in domains such as visuospatial/executive function and abstract reasoning. In addition, the attention and delayed recall tasks are not as challenging as that in MoCA. In practice, MoCA picks up more deficits in executive function, attention, and delayed recall. ${ }^{16}$ This study did not reproduce the superiority to MMSE and this may be related to the low education level of Chinese older adults. Due to the Chinese Civil War from 1927 to 1950 , the majority of elderly Chinese individuals did not receive much education and many were illiterate. According to published data, ${ }^{17}$ the average number of years of education for elderly Chinese individuals is about 5 years, which is significantly less than that of their western counterparts.

The validity of HK-MoCA is based on its non-inferiority to CMMSE. This study compared
HK-MoCA with CMMSE using a new cutoff point derived from the same study and found comparable sensitivity and specificity in detection of MCI. If the CMMSE cutoff as suggested by Chiu et $\mathrm{al}^{4}$ was utilised, HK-MoCA is definitely more sensitive. As such, HK-MoCA is relatively easy to use (both required less than 15 minutes to administer) and incorporates important domains missed in CMMSE. It is a clinically efficient and effective screening instrument and can be generalised for use in Chinese older adults with MCI or dementia. Customarily, many memory clinics utilise MMSE as a screening tool as it is convenient to use and available free of charge. Considering the ceiling effect of MMSE due to the low level of task difficulty and the copyright fees introduced recently, validated HK-MoCA provides an attractive alternative.

\section{Psychometric properties of the Hong Kong version of Montreal Cognitive Assessment}

Montreal Cognitive Assessment is one of the common cognition screening instruments used locally and worldwide. It is commonly used to discriminate cognitive impairment due to various causes. In Hong Kong, there was only one validation study conducted by Wong et $\mathrm{al}^{13}$ involving use of HK-MoCA in patients with cerebral SVD. They demonstrated that HK-MoCA differentiated SVD patients from controls (AUC=0.81) with an optimal cutoff at 21/22. This cutoff point was valid to predict SVD patients with cognitive impairment only, although in clinical practice, it was commonly used to discriminate cognitive impairment of various causes. This study successfully generalised the validity of HK-MoCA for identifying $\mathrm{MCI}$ and dementia in Chinese older adults, and determined the optimal cutoff points of these conditions. The optimal cutoff points yielded were similar to those in previous studies in China ${ }^{8,10}$ and $\mathrm{Korea}^{7}$ using the same descended educational adjustment. The HK-MoCA is useful for detecting persons with cognitive impairment in Chinese older adult population and a score of below 22 should prompt detailed diagnostic investigations. The results demonstrated good intra-rater and inter-rater reliability and internal consistency. It showed good convergent validity with CMMSE and GDS scores as well. Besides, the study investigated the effect of education on this cognitive screening instrument with respect to the low education level of Chinese older adults and employed a descended education adjustment from 12 to 6 years of education. This descended education adjustment is supported by studies conducted in China ${ }^{8}$ and Korea. ${ }^{7}$

\section{Limitations}

There were several limitations to the HK-MoCA. This instrument required the participants to follow verbal and written commands, hence the performance of 
elderly with hearing or visual impairment would be affected. Illiterate or poorly educated persons might have difficulty in comprehending the instructions and the cube and clock drawing tasks were too difficult. Furthermore, stroke patients whose dominant hand has been affected might not be able to perform the drawing test.

In this study, subjects were recruited from a local general hospital situated in a lower social class residential area. Three quarters of the participants received primary education or less. The descended education adjustment from 12 to 6 years of education should be subject to review with respect to the trend of education received by older adults. Besides, short break between CMMSE and HK-MoCA administration might not totally relieve the fatigue error. One might argue that geriatricians and psychogeriatricians in this study were not blinded from the HK-MoCA, CMMSE and GDS scores, which might have introduced bias when they made the final cognitive diagnosis. Furthermore, inter-rater reliability established using convenience sampling of 20 participants being tested 2 to 4 weeks apart was not an optimal way to determine the concordance between the two co-investigators. Last but not the least, the predictive values could not be ascertained in this study as the patient groups and NC were not recruited consecutively from a designated population, leaving the true prevalence unknown. Further study can explore the ability of HK-MoCA to grade the severity of cognitive impairment and predict long-term cognitive decline.

\section{Conclusion}

This study validated that HK-MoCA is a sensitive screening instrument for use in Chinese older adults in Hong Kong with MCI or dementia, irrespective of the underlying aetiology. This validated HK-MoCA is brief and feasible to conduct in the clinical setting, and can be completed in less than 15 minutes. It is an attractive alternative screening instrument to MMSE which has ceiling effect and needs to be purchased due to copyright issues. A score of less than 22 should prompt further diagnostic assessment.

\section{Acknowledgement}

The authors thank Dr Ziad S Nasreddine for his permission to use the Hong Kong version of Montreal Cognitive Assessment test.

\section{Declaration}

No conflicts of interest were declared by authors.

\section{References}

1. Lam LC, Tam CW, Lui VW, et al. Prevalence of very mild and mild dementia in community-dwelling older Chinese people in Hong Kong. Int Psychogeriatr 2008;20:135-48.

2. Damian AM, Jacobson SA, Hentz JG, et al. The Montreal Cognitive Assessment and the mini-mental state examination as screening instruments for cognitive impairment: item analyses and threshold scores. Dement Geriatr Cogn Disord 2011;31:126-31.

3. Folstein MF, Folstein SE, McHugh PR. "Mini-mental state". A practical method for grading the cognitive state of patients for the clinician. J Psychiatr Res 1975;12:189-98.

4. Chiu HF, Lee HC, Chung WS, Kwong PK. Reliability and validity of the Cantonese version of mini-mental state examination-a preliminary study. J Hong Kong Col Psychiatrists 1994;4:25-8.

5. Nasreddine ZS, Phillips NA, Bédirian V, et al. The Montreal Cognitive Assessment, MoCA: a brief screening tool for mild cognitive impairment. J Am Geriatr Soc 2005;53:6959.

6. Petersen RC, Smith GE, Waring SC, Ivnik RJ, Tangalos EG, Kokmen E. Mild cognitive impairment: clinical characterization and outcome. Arch Neurol 1999;56:303-8.

7. Lee JY, Lee DW, Cho SJ, et al. Brief screening for mild cognitive impairment in elderly outpatient clinic: validation of the Korean version of the Montreal Cognitive Assessment. J Geriatr Psychiatry Neurol 2008;21:104-10.

8. Wang YP, Xu GL, Yang SQ, Liu XM, Deng XY. Value of Montreal Cognitive Assessment in identifying patients with mild vascular cognitive impairment after first stroke. Chinese Journal of Neuromedicine 2010;9:503-7.

9. Reisberg B, Ferris SH, de Leon MJ, Crook T. The Global Deterioration Scale for assessment of primary degenerative dementia. Am J Psychiatry 1982;139:1136-9.

10. Tu QY, Jin H, Ding BR, et al. Reliability, validity, and optimal cutoff score of the Montreal Cognitive Assessment (Changsha version) in ischemic cerebrovascular disease patients of Hunan Province, China. Dement Geriatr Cogn Dis Extra 2013;3:25-36.

11. Rahman TT, El Gaafary MM. Montreal Cognitive Assessment Arabic version: reliability and validity prevalence of mild cognitive impairment among elderly attending geriatric clubs in Cairo. Geriatr Gerontol Int 2009;9:54-61.

12. Fujiwara Y, Suzuki H, Yasunaga M, et al. Brief screening tool for mild cognitive impairment in older Japanese: validation of the Japanese version of the Montreal Cognitive Assessment. Geriatr Gerontol Int 2010;10:225-32.

13. Wong A, Xiong YY, Kwan PW, et al. The validity, reliability and clinical utility of the Hong Kong Montreal Cognitive Assessment (HK-MoCA) in patients with cerebral small vessel disease. Dement Geriatr Cogn Disord 2009;28:81-7.

14. American Psychiatric Association. Diagnostic and Statistical Manual of Mental Disorders, 4th ed. Washington, DC: American Psychiatric Association; 1994.

15. Elderly Commission: prevalence of dementia in Hong Kong, 2006. Available from: http://www.elderlycommission.gov. hk/en/meeting/47.html. Accessed Jun 2011.

16. Wong A, Kwan P, Chan AY, et al. The validity, reliability and utility of the Cantonese Montreal Cognitive Assessment (MoCA) in Chinese patients with confluent white matter lesions. Hong Kong Med J 2008;14(Suppl 6):7S.

17. Chan AS, Choi A, Chiu H, Lam L. Clinical validity of the Chinese version of Mattis Dementia Rating Scale in differentiating dementia of Alzheimer's type in Hong Kong. J Int Neuropsychol Soc 2003;9:45-55. 